\title{
Metformin Inhibited Growth, Invasion and Metastasis of Esophageal Squamous Cell Carcinoma in Vitro and in Vivo
}

\author{
Feng Liang ${ }^{\mathrm{a}} \quad$ Yu-Gang Wang ${ }^{\mathrm{b}} \quad$ Changcheng Wang ${ }^{\mathrm{a}}$ \\ aDepartment of Gastroenterology, Huai'an Second People's Hospital, The Affiliated Huai'an Hospital \\ of Xuzhou Medical University, Huai'an, 'Department of Gastroenterology, Shanghai Tongren Hospital, \\ Shanghai Jiao Tong University School of Medicine, Shanghai, China
}

\author{
Key Words \\ Metformin • Esophageal squamous cell carcinoma • Invasion • Migration • Metastasis
}

\begin{abstract}
Background/Aims: This study aimed at investigating the effects of metformin on the growth and metastasis of esophageal squamous cell carcinoma (ESCC) in vitro and in vivo. Methods: Two human ESCC cell lines EC9706 and Eca109 were selected and challenged with metformin in this study. Western blot assay was performed to detect th level of $\mathrm{BCl}-2, \mathrm{Bax}$ and Caspase-3. Scratch wound assay, transwell assay and Millicell invasion assay were used to assay the invasion and migration of EC9706 and Eca109 cells. Nude mice tumor models were used to assay the growth and lung metastasis of ESCC cells after metformin treatment. The plasma glucose level was also assayed. Results: We found that metformin significantly inhibited proliferation and induced apoptosis of both ESCC cell lines in a dose- and time-dependent manner, and the expression of $\mathrm{Bcl}-2$ was down-regulated and Bax and Caspase- 3 were upregulated. Metformin significantly inhibited the invasion and migration of EC9706 and Eca109 cells $(p<0.05)$. mRNA and protein levels of MMP- 2 and MMP- 9 decreased significantly upon treatment with metformin of $10 \mathrm{mM}$ for 12,24 and $48 \mathrm{~h}$ in a time-dependent manner $(p<$ $0.05)$. In line with in vitro results, in vivo experiments demonstrated that metformin inhibited tumorigenicity, inhibited lung metastasis and down-regulated the expression of MMP-2 and MMP-9. Moreover, we showed that metformin treatment did not cause significant alteration in liver and renal functions and plasma glucose level. Conclusion: Our study for the first time demonstrated the anti-invasive and anti-metastatic effects of metformin on human ESCC cells both in vitro and in vivo, which might be associated with the down-regulation of MMP-2 and MMP-9. As a whole, our results indicate the potential of metformin to be developed as a chemotherapeutic agent for patients with ESCC and might stimulate future studies on this area.

F. Liang and Y.-G. Wang contributed equally to this work.

\begin{tabular}{ll}
\hline Changcheng Wang & Department of Gastroenterology, Huai'an Second People's Hospital \\
& The Affiliated Huai'an Hospital of Xuzhou Medical University, Huai'an 223002 (China) \\
& E-Mail dr_wang1@aliyun.com
\end{tabular}




\section{Introduction}

Metformin is an antidiabetic drug with excellent safety records in patients with diabetes that can improve insulin sensitivity, inhibits hepatic gluconeogenesis and decreases glycogenolysis [1]. Recently, increasing evidence has shown that metformin is capable of reducing risk of and/or improving prognosis of some types of cancer in patients with or without type II diabetes [2-7]. Experimental studies have shown the antitumor activities of metformin in multiple cancers such as liver [8], lung [9], pancreas [10], ovary [11] and gastric cancer [12]. Moreover, metformin has entered into clinic trails as a chemopreventive or chemotherapeutic agent against tumors $[6,7,13,14]$ and has shown promise in several tumors $[6,7,13]$.

Esophageal cancer represents the sixth leading cause of cancer death worldwide. Most patients of esophageal cancer are diagnosed at advanced stages of the disease due to lack of alarming symptoms at an early stage and are thus no longer suitable for curative surgery $[15,16]$. Moreover, it was reported that about $20 \%$ of patients experience a recurrence after curative esophagectomy [4]. Unlike cancers such as breast cancer and colon cancer whose prognoses have been improved significantly during the last several decades, the outcome of ESCC remains largely unchanged with a 5-year survival rate being $15 \%$ to $25 \%$ [15]. Therefore, developing novel preventive and/or therapeutic strategies for this deadly disease remains urgently needed.

Previous studies have demonstrated that metformin possesses anti-proliferative and pro-apoptotic effects on esophageal squamous cell carcinoma (ESCC) [17-20]. However, the effects of metformin on the invasiveness and metastasis of ESCC have not been reported yet. In this study, we validated the anti-proliferative and pro-apoptotic effects of metformin on ESCC cells, then explored the effects and underlying mechanisms of metformin on the invasion and metastasis of human ESCC in vitro and in vivo, with the hope of providing theoretical basis for the development of metformin as a chemo-preventive or chemotherapeutic agents against ESCC.

\section{Materials and Methods}

\section{Reagents}

Metformin was purchased from Sigma-Aldrich (St. Louis, MO) and diluted in DMEM medium and stored at $-20^{\circ} \mathrm{C}$. Antibodies used for Western blot (WB) analysis and Immunohistochemical (IHC) staining were from the following sources: anti-Bax (used at 1:1500), Bcl-2 (used at 1:1500), caspase-3 (used at 1:1000), MMP-2 (used at 1:2000 for WB and 1:200 for IHC), MMP-9 (used at 1:2000 for WB and 1:200 for IHC) were from Santa Cruz Biotechnology (Santa Cruz, CA).

\section{Cell lines and animals}

Human ESCC lines EC9706 and Eca109 were purchased from Shanghai institute of cell research (Shanghai, China). All cells were cultured in Dulbecco's modified Eagle's (DMEM) medium (Gaithersburg, MD, USA) supplement with $10 \%$ fetal bovine serum (FBS, Gaithersburg, MD, USA) and $100 \mathrm{mg} / \mathrm{ml}$ penicillin/ streptomycin at $37^{\circ} \mathrm{C}$ in a humidified atmosphere of $5 \% \mathrm{CO}_{2}$.

5-6 weeks old male BALB/c nude mice were purchased from Shanghai institute of experimental animal breeding center and housed in a specific pathogen-free facility of experimental animal center of Xuzhou Medical College.

\section{Determination of growth curve}

Cells were seeded at 500 cells per well in 96-well plates and incubated in medium containing $10 \%$ FBS. 24 hours after seeding, cells were treated with metformin $(0,1,5,10,20,40 \mathrm{mM})$ for 24, 48, 72, 96 and $120 \mathrm{~h}$ respectively. At the indicated intervals, CCK-8 (Cell Counting Kit-8) 10 $\mu \mathrm{L}$ was added to each well and incubated for 4 hours at $37^{\circ} \mathrm{C}$. The absorbance at $450 \mathrm{~nm}$ was measured using the microplate reader (BioTek instruments, USA). The percentage of surviving cells from each group relative to controls was calculated 


\section{Cellular Physiology Cell Physiol Biochem 2018;51:1276-1286 \begin{tabular}{ll|l} 
and Biochemistry Published online: 27 November 2018 & $\begin{array}{l}\text { (c) } 2018 \text { The Author(s). Published by S. Karger AG, Basel } \\
\text { www.karger.com/cpb }\end{array}$ \\
\hline
\end{tabular}}

Liang et al.: Metformin Acts as an Inhibitor in ESCC

according to following formula: Viable cell $(\%)=\left(\mathrm{OD}_{\mathrm{nt}} / \mathrm{OD}_{\mathrm{n} 0}\right) \times 100 \%$, where $\mathrm{OD}_{\mathrm{nt}}$ stands for absorbance (OD) value of metformin treatment group and $\mathrm{OD}_{\mathrm{n} 0}$ for that of control group.

Annexin V/PI staining and TUNEL staining for apoptotic cells

Apoptosis was assessed by measuring membrane redistribution of phosphatidylserine using an annexin V-FITC apoptosis detection kit (KeyGen Biotech, Nanjing) according to the manufacturer's instructions. Percentage of Annexin V-FITC+ cells was represented as apoptosis rate. Cells were seeded in 6-well plates and incubated in medium containing 10\% FBS. 24 hours after seeding, cells were treated with metformin $(0,1,5,10,20,40 \mathrm{mM})$ for $48 \mathrm{~h}$. Cell apoptosis with Annexin V/PI staining was analyzed by a FACS Calibur flow cytometer (BD, Franklin Lakes, NJ, USA). Basal apoptosis and necrosis were identically determined on untreated cells. The TUNEL apoptosis test was performed with a TUNEL Apoptosis Detection Kit (Vazyme biotech, China) as described in the manufacturer's instructions.

\section{Scratch wound migration assay}

Cells were seeded at $4 \times 10^{5}$ cells per well in 6-well plates and incubated in medium containing $10 \%$ FBS. 24 hours after seeding, cells were treated with medium containing $10 \mathrm{mM}$ metformin or control medium for $0,12,24,48 \mathrm{~h}$, respectively. A scratch wound was made across each well of the 6 -well plate using a pipette tip. Loosely held cells were removed. Images were taken and area of the wound closed was calculated using image $\mathrm{J}$ software according to the following formula: migration index $(\mathrm{Im})=\left(\mathrm{W}_{0}-\mathrm{Wt}\right) / \mathrm{W}_{0} \times$ $100 \% \mathrm{~W}_{0}$ represents the initial width of scratching, Wt represents scratching width hours after.

\section{Transwell Migration analysis}

EC9706 and Eca109 cells were incubated in medium containing metformin $10 \mathrm{mM}$ and without metformin as control group for $24 \mathrm{~h}$, and collected by trypsinization and resuspended. Cells $\left(1 \times 10^{5} / \mathrm{ml}\right)$ about $200 \mu \mathrm{L}$ in serum-free medium were placed into the upper chamber ( $8 \mu \mathrm{L}$ pore size, Millipore) in the 24 -well plates, medium containing $10 \%$ FBS was added to the lower chamber. The membrane containing migrating cells was fixed by methanol and stained by crystal violet. $12 \mathrm{~h}$ later, non-migrating cells on the upper side of the membrane were removed with cotton swabs. The average number of cells on the lower side was calculated after images were taken by optical microscope.

\section{Invasion analysis}

Cells were collected by trypsinization and resuspended in serum-free medium $\left(3 \times 10^{5} / \mathrm{ml}\right)$ as in the migration analysis. Cells $\left(1 \times 10^{5} / \mathrm{ml}\right)$ in serum-free medium were placed into the upper wells of the 24 -well plates, coated with $80 \mu \mathrm{L}$ of Matrigel (1:7 dilution) of the Millicell ( $8 \mu \mathrm{L}$ pore size, Corning) with metformin $10 \mathrm{mM}$. Medium containing 20\% FBS was added to the lower chamber. Cell invasion into the Matrigel was determined following $24 \mathrm{~h}$ under standard culture condition. The membrane containing invasion cells was fixed by methanol and stained by crystal violet after non-invading cells on the upper side of the membrane were removed with cotton swabs. The average number of cells on the lower side was calculated after images were taken by optical microscope.

\section{Reverse transcription PCR (RT-PCR)}

Total RNA was extracted using TRIZol reagent (Invitrogen, Carlsbad, CA, USA) according to the manufacturer's recommendations, and then reversed transcription into cDNA. The PCR reaction was performed in the presence of Taq DNA polymerase, dNTP mix, and PCR buffer primers (all from TIAN GEN, China). After denaturation at $94^{\circ} \mathrm{C}$ for $3 \mathrm{~min}$, the samples underwent 35 cycles of amplification 30 sec at $94^{\circ} \mathrm{C}, 1 \mathrm{~min}$ at $64^{\circ} \mathrm{C}$ for Bax and Bcl-2, or $60^{\circ} \mathrm{C}$ for Caspase-3, GAPDH and MMP-9 or $55^{\circ} \mathrm{C}$ for MMP-2, and $1 \mathrm{~min}$ at $72^{\circ} \mathrm{C}$ with a $10 \mathrm{~min}$ extension at $72^{\circ} \mathrm{C}$ following the last cycle. The primers were synthesized by ShengGong, ShangHai: 5'- AGG ATC GAG CAG GGC GAA TG-3' and 5'-GCT CCC GGA GGA AGT CCA AT-3' for Bax, 5'-GAT GGC AAA TGA CCA GCA GA-3' and 5'-GCA GGA TAG CAG CAC AGG AT-3' for Bcl-2, 5'-GAC TCT GGA ATA TCC CTG GAC AAC A-3' and 5'- AGG TTT GCT GCA TCG ACA TCT G-3' for Caspase-3, 5'- TTG GTG TAG GTG TAA ATG GGT G -3' and 5'-TGG CAA GTA CGG CTT CTG TC -3' for MMP-2, 5'-AAC TCA CGC GCC AGT AGA AG -3' and 5'- GAG GTG GAC CGG ATG TTC C -3' for MMP-9, 5'-TGT TGC CAT CAA TGA CCC CTT-3' and 5'-CTC CAC GAC GTA CTC AGC G-3' for GAPDH. Products were electrophoresed on $1.5 \%$ agarose gels containing 0.5 $\mu \mathrm{g} / \mathrm{mL}$ ethidium bromide (EB). 


\section{Cellular Physiology Cell Physiol Biochem 2018;51:1276-1286 \begin{tabular}{l|l|l} 
and Biochemistry Published online: 27 November 2018 & $\begin{array}{l}\text { C } 2018 \text { The Author(s). Published by S. Karger AG, Basel } \\
\text { www.karger.com/cpb }\end{array}$ \\
\hline DOI. 1159/0049559
\end{tabular}}

Liang et al.: Metformin Acts as an Inhibitor in ESCC

\section{Western blotting analysis}

Protein expression levels were determined by Western blot analysis as previously described [21]. Briefly, cells were lysed in Laemmli buffer $(62.5 \mathrm{mM}$ Tris-HCl pH 6.8, 2\%SDS, $10 \%$ glycerol, $50 \mathrm{mM}$ dithiothreitol, $0.01 \%$ bro-mophenol blue) for 5 minutes at $95^{\circ} \mathrm{C}$ post treatment. Cell lysates were resolved by SDS/PAGE and transferred electrophoretically to Nitro cellulose membrane (Bio-Rad). Blots were probed with specific antibodies and immunoreactive proteins were revealed by BCIP/NBT assay kit (Santa Cruz Biotechnology) according to the manufacturer's instructions.

\section{Tumor xenograft model}

This animal experiment was approved by the Institutional Animal Care and Use Committee of Xuzhou Medical College. $200 \mu \mathrm{L}$ Eca109 cells (containing $2 \times 10^{6}$ cell) were implanted subcutaneously into the right flanks of each of the twenty-two nude mice. The animals were randomly divided into metformin group and control group (11 mice each group). Treatment was initiated when the tumors reached a mean diameter of 5 $\mathrm{mm}$ (10 days post implantation). Metformin was dissolved in purified water and was given to each mouse in metformin group once daily at $250 \mathrm{mg} / \mathrm{kg}$ (i.p., $100 \mu \mathrm{L}$ per mouse) [21]. The control group received vehicle

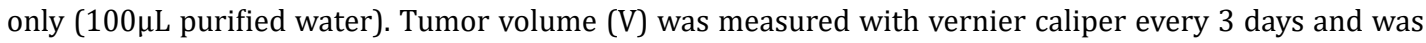
calculated as $V=0.52\left(A \times B^{2}\right) / 2$, in which $A$ represents the larger diameter of the tumor and $B$ the smaller diameter. 21 days later, all the animals were sacrificed. Primary tumors and other organs (brain, heart, lung, liver and kidney) were dissected manually. Part of tumors was homogenized into tumor lysis buffer for western blot analysis whereas the remaining tumors were reserved for immunohistochemical analysis. Tissues from tumors and other organs for histology were fixed in $4 \%$ formaldehyde or $10 \%$ formalin overnight, embedded in paraffin, and sectioned at $6 \mu \mathrm{m}$ with a microtome as previously reported [22]. Slices were subjected to Hematoxylin and Eeosin (H\&E) staining as previously reported [22].

\section{Cytotoxicity assays}

Blood was collected in heparin-coated tubes from each mouse prior to scarification. Plasma isolated from each blood sample were subjected to analysis of liver (AST [aspartate amino-transferase], ALT [alanine aminotransferase], albumin) and renal functions (BUN [blood urea nitrogen], Scr [serum creatinine]) as well as glucose level. All assays were performed using kits from Bioassay Systems (Huai'an, China). All assays were performed according to the manufacturer's instructions.

\section{Immunohistochemical (IHC) staining}

The expression of some apoptosis and metastasis associated proteins in xenograft tumor samples was determined by IHC staining. Briefly, $5 \mu \mathrm{m}$ thick paraffin-embedded tumor sections were deparaffinized and then rehydrated. Sections were subjected to heat-induced antigen-retrieval in citric acid buffer $(\mathrm{pH}$ 7.0) for $10 \mathrm{~min}$, blocked in $5 \%$ normal goat serum for $30 \mathrm{~min}$, and incubated in $3 \%$ hydrogen peroxide to suppress endogenous peroxidase activity. Sections were then treated with antibody at a dilution of 1:150 at $37^{\circ} \mathrm{C}$ for $4 \mathrm{~h}$, followed by peroxidase-conjugated antibody for $2 \mathrm{~h}$ at room temperature. Finally, sections were developed in a substrate solution of DAB ZSGB-Bio (Zhongshan, China); and counter-stained with hematoxylin. All sections were examined under light microscopy and the result was analyzed by Image J.

\section{Statistical analysis}

Each experiment or assay was performed at least for three times, and representative examples were shown. Data were reported as means \pm SD. The statistical significance of the differences was analyzed by Student's t-test. The value of $\mathrm{p}<0.05$ was considered significant. 


\section{Cellular Physiology Cell Physiol Biochem 2018;51:1276-1286

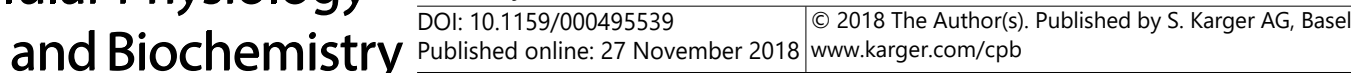 \\ Liang et al.: Metformin Acts as an Inhibitor in ESCC}

\section{Results}

\section{Anti-proliferative and pro-apoptosis effects of metformin on human ESCC cells}

EC9706 and Eca109 ESCC cells were treated by different concentrations $(0,1,5,10$, $20,40 \mathrm{mM}$ ) of metformin and the effects of metformin on proliferation of human ESCC were assessed at different time points (0h, $24,48,72,96,120 \mathrm{~h})$. As shown in Fig. $1 \mathrm{~A}$, metformin inhibited the proliferation of both of the ESCC cell lines in a dose- dependent and timedependent manner.

Next, we investigated the effects of metformin on the apoptosis of ESCC cells, which were treated with different concentrations $(0,1,5,10,20,40 \mathrm{mM})$ of metformin for $48 \mathrm{~h}$ and then were subjected to Annexin V/PI staining and flow cytometry. The results showed that as the doses of metformin increased from $1 \mathrm{mM}$ to $40 \mathrm{mM}$, the proportion of apoptotic tumor cells increased gradually in EC9706 (8.9\%, 14.8\%, 20.9\%, 51.7\% and 88.7\%, respectively) and Eca109 (10.4\%, 13.9\%, 17.4\%, 47.5\% and 73.6\%, respectively) cells (Fig. 1B).

The levels of apoptosis-related proteins and mRNA were measured from tumor cells treated with or without $10 \mathrm{mM}$ metformin for 12,24 and $48 \mathrm{~h}$ by western blot and RT-PCR. Upon metformin treatment, both protein and mRNA levels of Bcl-2 were significantly downregulated whereas those of Bax and Caspase- 3 were significantly up-regulated in a timedependent manner (Fig. 2A-D).

\section{Metformin inhibited migration and invasion of ESCC cells}

Scratch assay showed that treatment with metformin significantly inhibited the migration index of ESCC cells compared with those of control $(P<0.05)$ at time points of 12 , 24 and 48h, respectively (Fig. 3A). Migration assay showed that treatment with metformin $(10 \mathrm{mM}, 24 \mathrm{~h})$ inhibited the migration of EC9706 and Eca109 cells (Fig. 3B, left). Upon metformin treatment, the average numbers of EC9706 and Eca109 cells migrating to the lower chamber were significantly smaller ( $46.0 \pm 8.1$ and $35.7 \pm 8.1$, respectively) than those of control cells $(115.6 \pm 15.5,101.9 \pm 10.8$, respectively) (Fig. 3 C, upper) $(P<0.01)$. Similarly, Millicell assay showed that treatment with metformin $(10 \mathrm{mM}, 24 \mathrm{~h})$ inhibited the invasion of EC9706 and Eca109 cells (Fig. 3B, right), with the numbers of EC9706 and Eca109 cells penetrating Matrigel gel $(37.9 \pm 7.5$ and $21.3 \pm 6.2$, respectively) were significantly smaller than those of control cells $(104.7 \pm 10.7,106.8 \pm 8.1$, respectively) (Fig. 3C, lower) $(P<0.01)$.

To explore possible underlying mechanisms, we assayed the expression levels of MMP-2 and MMP-9 in metformin-treated and untreated cells. MMP- 2 and MMP-9 are key regulators of cancer cell invasion and metastasis [23]. The results of RT-PCR and western blot showed that mRNA and protein levels of MMP-2 and MMP-9 decreased significantly upon treatment with metformin of $10 \mathrm{mM}$ for 12,24 and $48 \mathrm{~h}$ in a time-dependent manner $(p<0.05)$ (Fig. 4).

Fig. 1. Effects of metformin on the proliferation and apoptosis of esophageal squamous cell c a r c i n o m a (ESCC) cells. (A). Metformin i $\mathrm{n} \mathrm{h} \mathrm{i} \mathrm{b} \mathrm{i} \mathrm{t} \mathrm{e} \mathrm{d}$ proliferation of EC9706 (left)

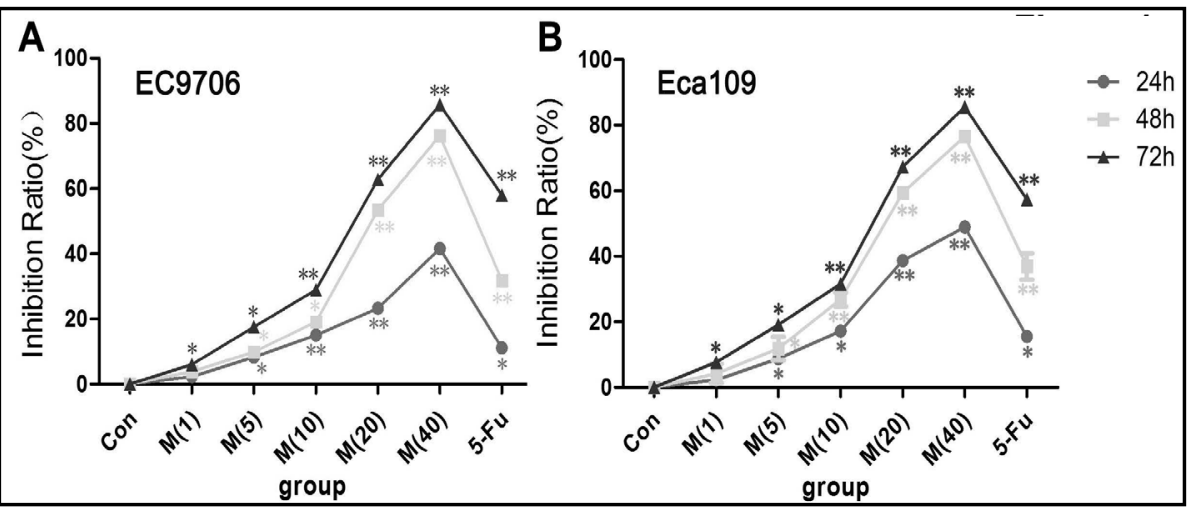
and Eca109 (right) cells in a time- and dose-dependent manner. (B). Metformin induced apoptosis of EC9706 (left) and Eca109 (right) cells dose-dependently. The results were the means \pm SD of three independent experiments. Con: control. Error bars: 95\% CI. 


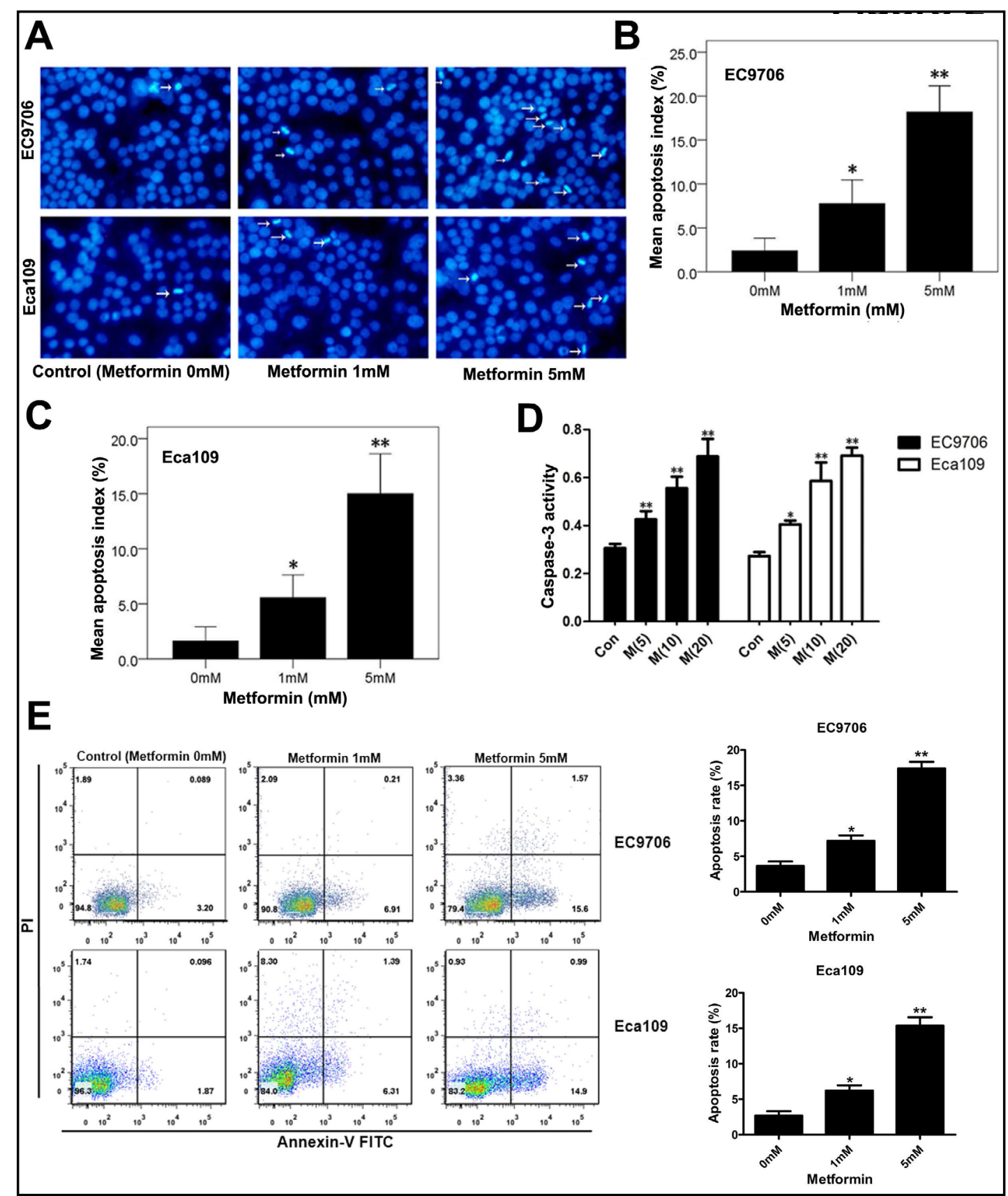

Fig. 2. Effects of metformin treatment on the expression levels of Bcl-2, Bax and Caspase- 3 in esophageal squamous cell carcinoma (ESCC) cells EC9706 and Eca109 as assayed by reserve-transcript PCR (RT-PCR) and western blot. (A, B). Metformin (10mM) significantly down-regulated Bcl-2 mRNA level whereas upregulated Bax and Caspase-3 mRNA expression in a time-dependent manner. (C, D) Metformin (10mM) significantly down-regulated Bcl-2 protein level whereas up-regulated Bax and Caspase-3 protein levels in a time-dependent manner. Data were representative of three independent experiments. ${ }^{*} \mathrm{P}<0.05,{ }^{* *} \mathrm{P}<0.01$ vs control group. Error bars: 95\% CI.

Metformin inhibited the growth of Eca109 cell xenografts in vivo

In a xenograft model of Eca109 cells, the average volume of tumors in metformin-treated group $(250 \mathrm{mg} / \mathrm{kg} / \mathrm{d}$, i.p., 21 consecutive days) was significantly smaller than that in control group (Fig. 5A, B), suggesting that metformin inhibited tumorigenicity in vivo.

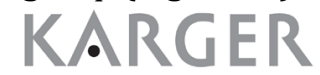




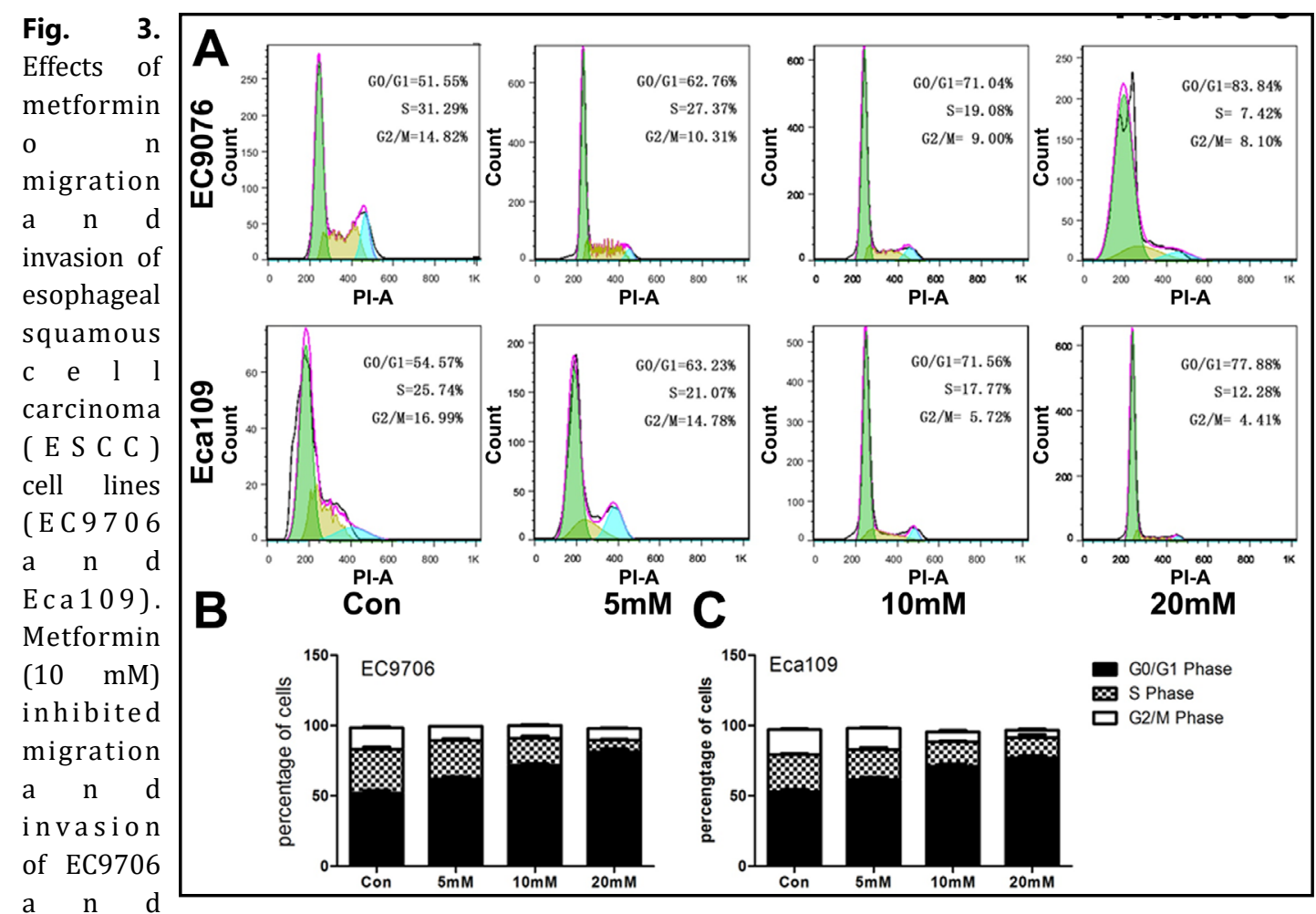

E c a 109

cells as assayed by scratch assay (A), migration assay (B left, C upper) and invasion assay (B right, C lower). ${ }^{*} \mathrm{P}<0.05,{ }^{* *} \mathrm{P}<0.01$ vs control group. Error bars: $95 \% \mathrm{CI}$.

Fig. 4. Effects of metformin on the expression levels of MMP-2 and MMP-9 in vitro. RT-PCR (A) and western blot (A) showed that mRNA and protein levels of MMP2 and MMP9 decreased significantly upon treatment with metformin of $10 \mathrm{mM}$ for 12 , 24 and $48 \mathrm{~h}$ in a time-dependent $m$ a $n$ n e $r$ $(\mathrm{p}<0.05)$. * $\mathrm{P}<0.05$, ** $\mathrm{P}<0.01 \quad$ vs control group. Error bars: 95\%

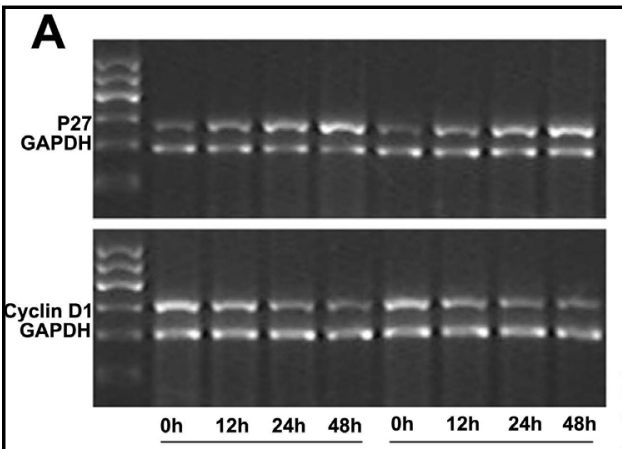

C

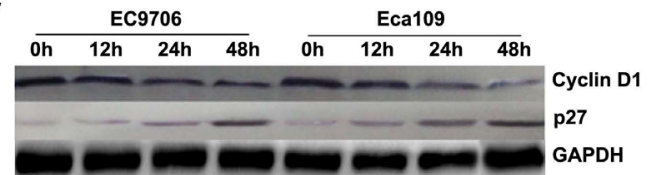

D

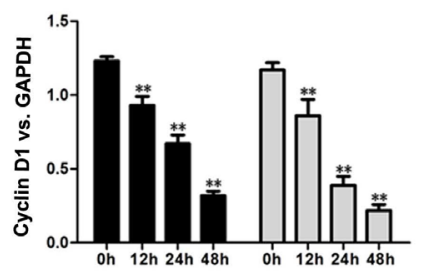

E
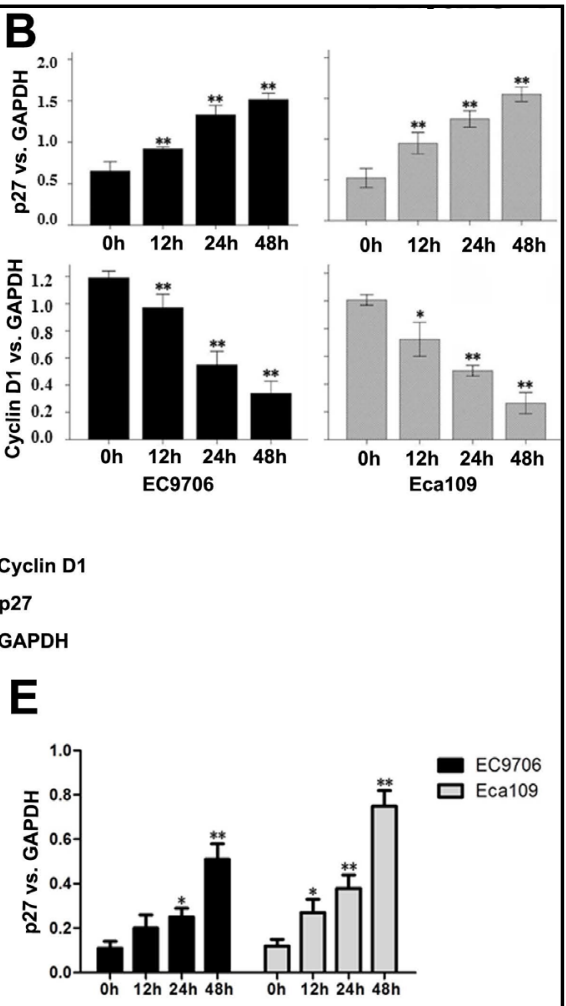
CI. 


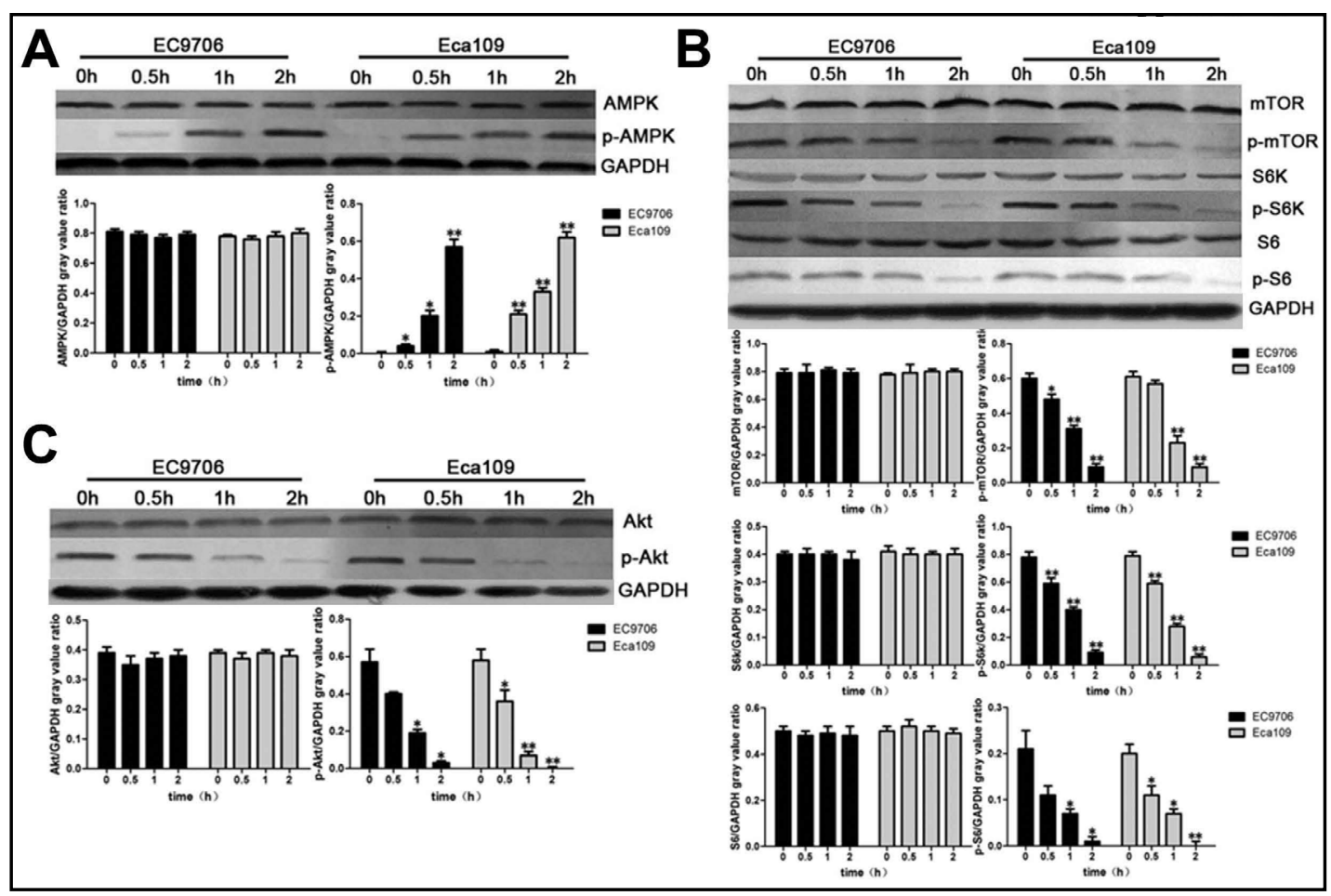

Fig. 5. Effects of metformin on tumorigenicity, liver and renal functions, as well as plasma glucose level in a xenografts mouse model of Eca109 cells. (A, B) Metformin inhibited tumorigenicity in vivo in that the average volume of tumors in metformin-treated group (250 mg/kg/d, i.p., 21 consecutive days, $\mathrm{n}=6)$ was significantly smaller than that in control group ( $\mathrm{n}=6)$. (C) Metformin treatment $(250 \mathrm{mg} / \mathrm{kg} / \mathrm{d}$, i.p., 21 consecutive days) did not significantly influence liver (AST, ALT, ALB, Glu) and renal (BUN, Scr) functions and plasma glucose level. AST: aspartate amino-transferase; ALT: alanine aminotransferase; AST: aspartate amino-transferase; ALT: alanine aminotransferase; ALB: albumin; BUN: blood urea nitrogen: Scr: serum creatinine. Error bars: $95 \%$ CI.

To investigate possible side effects of metformin, plasma samples of mice from metformin-treated and untreated groups were subjected to analysis of liver (AST, ALT, and albumin) and renal functions (BUN and Scr) as well as glucose level. As shown in Fig. 5C, compared with control, metformin treatment $(250 \mathrm{mg} / \mathrm{kg} / \mathrm{d}$, i.p., 21 consecutive days $)$ did not cause significant alterations in liver function, renal functions or glucose level, indicating that metformin is well tolerated in our mouse model.

\section{Metformin inhibited ESCC metastasis in vivo}

To explore the effects of metformin on tumor metastasis in vivo, brain, heart, lung, liver and kidney from each mouse were dissected manually and subjected to H\&E staining, the results of which showed that lung metastases were seen in the lungs of control mice but not in metformin-treated mice (Fig. 6A). Metastases were not detectable in liver, heart, brain or kidney in either group (Fig. 6A).

The expression levels of MMP-2 and MMP-9 significantly decreased in cancer samples from metformin group compared with those in control group (Fig. 6B) as assayed by immunohistology, and tunel staining with tumor tissue indicated that metformin treatment increases the apoptotic level of cancer cells in vivo, confirming the results of in vitro experiments. 
Fig. 6. Effects of metformin on cancer metastasis in a xenografts mouse model of Eca109 cells. (A) As shown by Hematoxylin and Eeosin (H\&E) staining, lung metastases were detectable in mice in control group $(\mathrm{n}=6)$ (black arrow in left pannel, $\times 10$ ) but not in metformin group ( $\mathrm{n}=6)$ (right pannel, $\times 10$ ). (B) The expression of MMP-2 and MMP-9 also significantly decreased in samples (primary tissue) of metformin group compared with those of control group. (C) Tunel staining of tumor tissue slide. ${ }^{* *} \mathrm{P}<0.01$ vs control group. Error bars: 95\% CI.

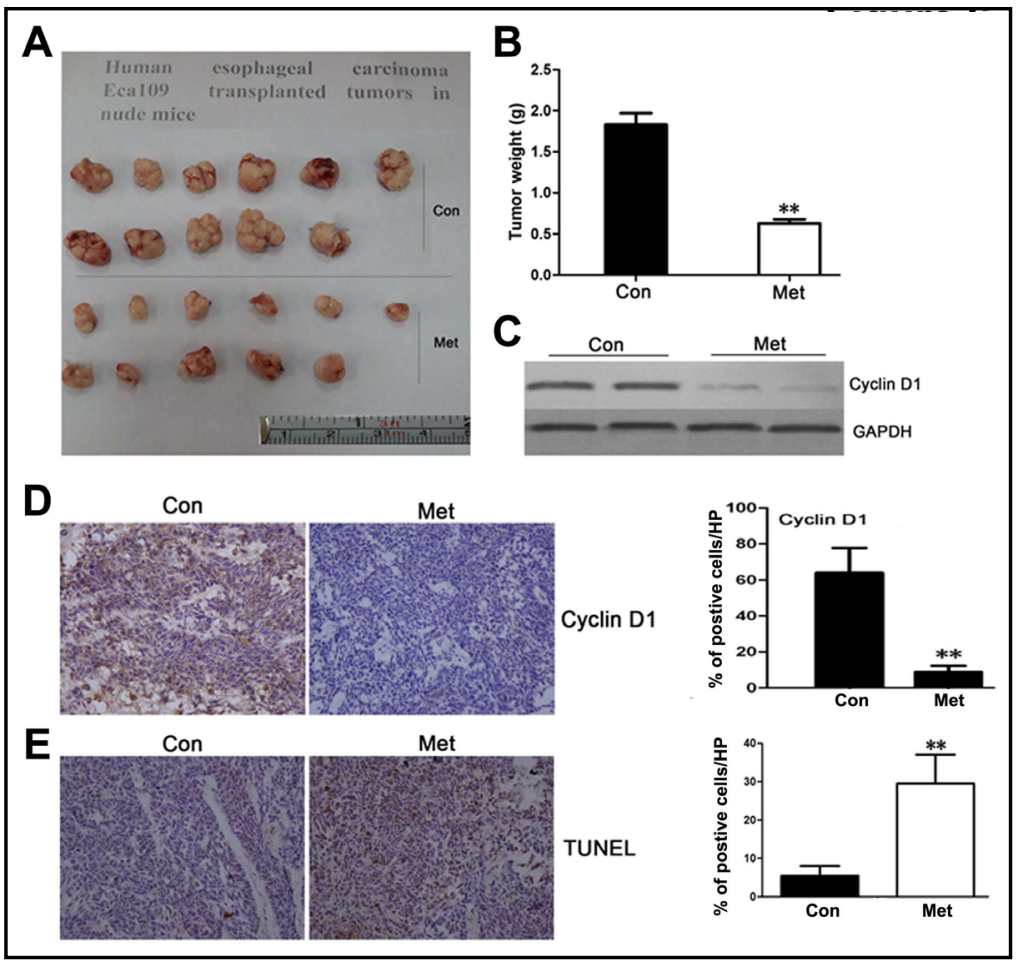

\section{Discussion}

Recently, there is an increasing body of clinical and preclinical studies regarding the preventive and therapeutic potentials of metformin on human cancers including esophageal cancer [2-14, 17-20]. For example, metformin was reported to inhibit cell growth and block cell-cycle in esophagus cancer cell lines [18, 20, 24]. Fujihara, et, al. found that metformin inhibits esophageal adenocarcinoma cell proliferation in vitro and in vivo [25]. Feng Y and colleagues reported that metformin promotes apoptosis in ESCC cells [19]. However, there were no reports on the effects of metformin on the invasion and metastasis of ESCC. To the best of our knowledge, ours is the first on this area.

In this study, we first investigated the effects of metformin on the proliferation and apoptosis of human ESCC cells, the results of which (Fig. 1A, B) confirmed previous reports that metformin can inhibit proliferation and induce apoptosis of ESCC cells [18-20, 24, 25]. As we know, Bcl-2, Bax and Caspase-3 are involved in apoptotic process [26, 27] and the relative levels of Bax and Bcl-2 are referred to as "life-death switch" [28] in which Bcl-2 promotes cell survival whereas Bax promotes cell apoptosis [27, 28]. Our results showed that the expression level of Bcl-2 was significantly down-regulated whereas those of Bax and Caspase-3 were significantly up-regulated upon metformin treatment (Fig. 2A-D), suggesting a possible mechanism underlying the pro-apoptosis effects of metformin.

In two human ESCC cell lines EC9706 and Eca109, we for the first time showed that metformin treatment inhibited the invasion and migration of human ESCC cells in vitro (Fig. 3). As modulators of the tumor microenvironment [23], the matrix metalloproteinases (MMPs) such as MMP-2 and MMP-9 catalyze the proteolysis of epithelial basement membrane, extracellular matrix and components of vascular, thus facilitating cancer invasion, intravasation and extravasation [23, 29-31]. Our study showed that metformin treatment down-regulated the expression levels of MMP-2 and MMP-9 in a time-dependent manner (Fig. 4), suggesting that metformin inhibited the invasion and migration of ESCC cells possibly through down-regulate MMP-2 and MMP-9. 


\section{Cellular Physiology Cell Physiol Biochem 2018;51:1276-1286 \begin{tabular}{ll|l} 
and Biochemistry Published online: 27 November 2018 & $\begin{array}{l}\text { (c) } 2018 \text { The Author(s). Published by S. Karger AG, Basel } \\
\text { www.karger.com/cpb }\end{array}$ \\
\hline
\end{tabular}}

Liang et al.: Metformin Acts as an Inhibitor in ESCC

Next, in a xenograft mouse model of Eca109 cells, we showed that metformin can inhibit tumorigenicity and metastasis. Compared with control, metformin treatment did not altered liver and renal functions and plasma glucose level significantly, suggesting that metformin is well tolerated and does not cause hypoglycemia in non-diabetic mice. In line with in vitro results, the expression levels of MMP-2 and MMP-9 in tumors of metformin group were significantly down-regulated compared with those of control group.

\section{Conclusion}

In conclusion, our study for the first time demonstrated the anti-invasive and antimetastatic effects of metformin on human ESCC cells both in vitro and in vivo, and we also demonstrated the safety of metformin in xenograft model of human ESCC. Moreover, our results suggest that the down-regulation of MMP-2 and MMP-9 might involve in the antiinvasive and anti-metastatic effects of metformin, which needs to be confirmed in future studies by knockdown/overexpression experiments. As a whole, our results indicate the potential of metformin to be developed as a chemotherapeutic agent for patients with ESCC and might stimulate future studies on this area.

\section{Disclosure Statement}

The authors declare to have no competing interests.

\section{References}

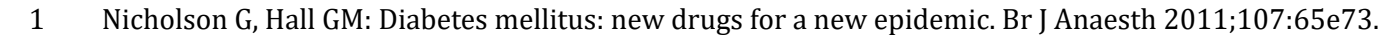

-2 Pollak MN: Investigating metformin for cancer prevention and treatment: the end of the beginning. Cancer Discov 2012;2:778-790.

-3 Taubes G: Cancer research. Cancer prevention with a diabetes pill? Science 2012;335:29.

4 Wan G, Yu X, Chen P, Wang X, Pan D, Wang X, Li L, Cai X, Cao F: Metformin therapy associated with survival benefit in lung cancer patients with diabetes. Oncotarget 2016 doi: 10.18632/oncotarget.8881.

5 Tseng $\mathrm{CH}$ : Metformin may reduce oral cancer risk in patients with type 2 diabetes. Oncotarget 2016;7):2000-8.

6 Chan AT: Metformin for cancer prevention: a reason for optimism. Lancet Oncol 2016;17:407-409.

7 Higurashi T, Hosono K, Takahashi H, Komiya Y, Umezawa S, Sakai E, Uchiyama T, Taniguchi L, Hata Y, Uchiyama S, Hattori A, Nagase H, Kessoku T, Arimoto J, Matsuhashi N, Inayama Y, Yamanaka S, Taguri M, Nakajima A: Metformin for chemoprevention of metachronous colorectal adenoma or polyps in postpolypectomy patients without diabetes: a multicentre double-blind, placebo-controlled, randomised phase 3 trial. Lancet Oncol 2016;17:475-483.

-8 Chen HP, Shieh JJ, Chang CC, Chen TT, Lin JT, Wu MS, Lin JH, Wu CY: Metformin decreases hepatocellular carcinoma risk in a dose-dependent manner: population-based and in vitro studies. Gut 2013;62:606-615.

$>9$ Li L, Han R, Xiao H, Lin C, Wang Y, Liu H, He Y: Metformin Sensitizes EGFR-TKI-Resistant Human Lung Cancer Cells In vitro and In vivo through Inhibition of IL-6 Signaling and EMT Reversal. Clin Cancer Res 2014;20:2714-2726.

$>10$ Nair V, Pathi S, Jutooru I, Sreevalsan S, Basha R, Abdelrahim M, Samudio I, Safe S: Metformin inhibits pancreatic cancer cell and tumor growth and downregulates $\mathrm{Sp}$ transcription factors. Carcinogenesis 2013;34:2870-9.

11 Shank JJ, Yang K, Ghannam J, Cabrera L, Johnston CJ, Reynolds RK, Buckanovich RJ: Metformin targets ovarian cancer stem cells in vitro and in vivo. Gynecol Oncol 2012; 127:390-397.

12 Kato K, Gong J, Iwama H, Kitanaka A, Tani J, Miyoshi H, Nomura K, Mimura S, Kobayashi M, Aritomo Y: The antidiabetic drug metformin inhibits gastric cancer cell proliferation in vitro and in vivo. Mol Cancer Therap 2012;11:549-560. 


\section{Cellular Physiology Cell Physiol Biochem 2018;51:1276-1286 \begin{tabular}{l|l|l} 
and Biochemistry Published online: 27 November 2018 & $\begin{array}{l}\odot 2018 \text { The Author(s). Published by S. Karger AG, Basel } \\
\text { www.karger.com/cpb }\end{array}$ \\
\hline
\end{tabular}}

Liang et al.: Metformin Acts as an Inhibitor in ESCC

13 Sivalingam V, McVey R, Gilmour K, Ali S, Roberts C, Renehan A, Kitchener H, Crosbie E: A presurgical window-of-opportunity study of metformin in obesity-driven endometrial cancer. Lancet 2015;385 Suppl 1:S90.

14 Kordes S, Pollak MN, Zwinderman AH, Mathôt RA, Weterman MJ, Beeker A, Punt CJ, Richel DJ, Wilmink JW: Metformin in patients with advanced pancreatic cancer: a double-blind, randomised, placebo-controlled phase 2 trial. Lancet Oncol 2015;16:839-847.

15 Pennathur A, Gibson MK, Jobe BA, Luketich JD: Oesophageal carcinoma. Lancet 2013;381:400-412.

$\$ 16$ Belkhiri A, El-Rifai W: Advances in targeted therapies and new promising targets in esophageal cancer. Oncotarget 2015;6:1348-1358.

17 Fujihara S, Kato K, Morishita A, Iwama H, Nishioka T, Chiyo T, Nishiyama N, Miyoshi H, Kobayashi M, Kobara H, Mori H, Okano K, Suzuki Y, Masaki T: Antidiabetic drug metformin inhibits esophageal adenocarcinoma cell proliferation in vitro and in vivo. Int J Oncol 2015;46:2172-2180.

-18 Xu Y, Lu S: Metformin inhibits esophagus cancer proliferation through upregulation of USP. Cell Physiol Biochem 2013;32:1178-1186.

-19 Feng Y, Ke C, Tang Q, Dong H, Zheng X, Lin W, Ke J, Huang J, Yeung SC, Zhang H: Metformin promotes autophagy and apoptosis in esophageal squamous cell carcinoma by downregulating Stat 3 signaling. Cell Death Dis 2014;5:e1088.

20 Cai X, Hu X, Tan X, Cheng W, Wang Q, Chen X, Guan Y, Chen C, Jing X: Metformin Induced AMPK Activation, G0/G1 Phase Cell Cycle Arrest and the Inhibition of Growth of Esophageal Squamous Cell Carcinomas In vitro and In vivo. PLoS One 2015;10:e133349.

21. Kisfalvi K, Eibl G, Sinnett-Smith J, Rozengurt E: Metformin disrupts crosstalk between G protein-coupled receptor and insulin receptor signaling systems and inhibits pancreatic cancer growth. Cancer Res 2009, 69:6539-6545.

-22 Chen S, Xue Y, Wu X, Le C, Bhutkar A, Bell EL, Zhang F, Langer R, Sharp PA: Global microRNA depletion suppresses tumor angiogenesis. Genes Dev 2014;28:1054-1067.

23 Kessenbrock K, Plaks V, Werb Z: Matrix metalloproteinases: regulators of the tumor microenvironment. Cell 2010;141:52-67.

24 Kobayashi M, Kato K, Iwama H, Fujihara S, Nishiyama N, Mimura S, Toyota Y, Nomura T, Nomura K,Tani J, Miyoshi H, Kobara H, Mori H, Murao K, Masaki T: Antitumor effect of metformin in esophageal cancer: in vitro study. Int J Oncol 2013;42:517-524.

-25 Fujihara S, Kato K, Morishita A, Iwama H, Nishioka T, Chiyo T, Nishiyama N, Miyoshi H, Kobayashi M, Kobara H, Mori H, Okano K, Suzuki Y, Masaki T: Antidiabetic drug metformin inhibits esophageal adenocarcinoma cell proliferation in vitro and in vivo. Int J Oncol 2015;46:2172-2180.

-26 Yasmeen A, Beauchamp MC, Piura E, Segal E, Pollak M, Gotlieb WH: Induction of apoptosis by metformin in epithelial ovarian cancer: involvement of the Bcl-2 family proteins. Gynecol Oncol 2011, 121:492-498.

27 Adams JM, Cory S: The Bcl-2 protein family: arbiters of cell survival. Science 1998;281:1322-1326.

28 Cory S, Adams JM: Killing cancer cells by flipping the Bcl-2/Bax switch. Cancer Cell 2005;8:5-6.

-29 Taras D, Blanc JF, Rullier A, Dugot-Senant N, Laurendeau I, Vidaud M, Rosenbaum J: Pravastatin reduces lung metastasis of rat hepatocellular carcinoma via a coordinated decrease of MMP expression and activity. J Hepatol 2007;46:69-76.

-30 Song J, Wu C, Korpos E, Zhang X, Agrawal SM, Wang Y, Faber C, Schäfers M, Körner H, Opdenakker G, Hallmann R, Sorokin L: Focal MMP-2 and MMP-9 activity at the blood-brain barrier promotes chemokineinduced leukocyte migration. Cell Rep 2015;10:1040-1054.

-31 Che YL, Luo SJ, Li G, Cheng M, Gao YM, Li XM, Dai JM, He H, Wang J, Peng HJ, Zhang Y, Li WY, Wang H, Liu B, Linghu H: The C3G/Rap1 pathway promotes secretion of MMP-2 and MMP-9 and is involved in serous ovarian cancer metastasis. Cancer Lett 2015;359:241-249. 